\title{
¿VOLUNTAD DE VIVIR O VOLUNTAD DE MORIR? EL SUICIDIO EN SCHOPENHAUER Y MAINLÄNDER
}

\author{
Sandra Baquedano \\ <sandrabaquedano@hotmail.com>
}

\begin{abstract}
Resumen
El apego a la vida suele ser más fuerte que todas las miserias del mundo, y aunque muchos juzguen que la vida no vale la pena ser vivida, son pocos los que se suicidan. Esto se debe a que el querer la vida no implica más que el que se la quiera. En este hecho radica el que expongamos y cuestionemos en este artículo la esencialidad del querer, a la luz de la voluntad de vivir y la voluntad de morir. ¿Aquello que queremos es realmente la vida o simplemente vivimos para liberarnos de ella?
\end{abstract}

Palabras Clave: suicidio, querer la vida, Schopenhauer, Mainländer.

\begin{abstract}
The will to live is usually stronger than all of the misery in the world, and although many consider that life is not worth living, only a few commit suicide. This is due to the fact that wanting to live does not imply more than living life. From this fact springs forth what we will talk about and question in this article, the essential of wanting, in light of the will to live and the will to die. Is that what we want really life or do we simply live to liberate ourselves from it?
\end{abstract}

Keywords: suicide, will to live, Schopenhauer, Mainländer.

\footnotetext{
$\overline{R Q}$

Leemos en El mundo como voluntad y representación: "Lejos de ser una negación de la voluntad, el suicidio es un fenómeno de la más fuerte afirmación de la voluntad. Pues la esencia de la negación es que no se detesta el sufrimiento, sino los goces de la vida. El suicida quiere la vida y sólo se halla descontento de las condiciones en las cuales se encuentra. Por eso, al destruir el fenómeno individual, no renuncia en modo alguno a la voluntad de vivir, sino tan sólo a la vida. Él quiere la vida, quiere una existencia y una afirmación sin trabas del cuerpo, pero el entrelazamiento de las circunstancias no se lo permite y ello le origina un enorme sufrimiento" (Schopenhauer 1986, Tomo I, §69, p. 541).

Cuando la explicación del suicidio se aborda desde la sociología o la psicología, se impone en general el discurso crítico que persigue su prevención. La metafísica de la voluntad de vivir no está exenta de aquella tendencia. Bajo la perspectiva de un noumeno volente, el suicidio no es considerado señal de querer dejar de vivir, por el
} 
contrario, resulta ser la manifestación más fehaciente de aceptar y afirmar una vida sin sufrimientos. Sin embargo, cuando las circunstancias no permiten gozar de esa vida o simplemente no permiten superar la condición sufriente en ella, el individuo obra, según Schopenhauer, conforme a su naturaleza como "voluntad metafísica", a la cual, al estar fuera del principium individuationis, le es indiferente la permanencia de cada individuo en particular. Esto último nos podría llevar a una aparente contradicción si consideramos que el fin de la voluntad es perpetuarse en el ser, a través de muchos individuos que ayudan a conservar la especie. Sin embargo, tal argumentación es fácilmente refutable si consideramos que no todos los individuos son aptos para la especie y, por lo tanto, útiles para cumplir aquel objetivo de la voluntad. Para Schopenhauer, el hecho de que la voluntad, por sobre el fenómeno del nacimiento y la muerte, jamás deje de manifestarse, es argumentación suficiente para condenar el suicidio. Con éste se niega el individuo, precisamente a esto remite la raíz latina sui del suicaedere (matar a uno mismo), es decir, se destruye el yo en particular, pero no se niega la voluntad ni por lo tanto la especie. En otras palabras, la destrucción voluntaria del cuerpo es la destrucción aparente y fenoménica de la objetivación más directa de la voluntad, mientras que ella, la cosa en sí, al no ser negada, permanece intacta. Al no negarse la voluntad, la nada es ilusoria. "Y él cree arreglar su miseria/A través de la muerte./¡Cómo se ha engañado!/Aquí se escondió detrás de un arbusto/Ahí está solo y desnudo, / Y todo lo que aquí le horrorizó / Está en él prolongado / ¡Cómo se ha engañado!" (Claudius 1974, p. 624-625).

La condena de orden moral que surge de la metafísica del noumeno volente se resume en el hecho de que el suicida no puede dejar de querer. El acto de darse muerte a sí mismo es resultado de afirmar en la adversidad las ganas de haber llevado una vida más afortunada, sin tormentos, sin embargo, al no haber podido satisfacer en esencia ya "nada" en ella, el suicida suprime el fenómeno, en este tiempo y en este lugar, dejando la cosa en sí intacta. El suicida detesta el sufrimiento, a diferencia del renunciante que detesta los goces de la vida. El primero afirma la voluntad de vivir suprimiendo el fenómeno de la vida. El segundo, en cambio, niega la esencia de ella, es decir, niega el querer vivir.

Un dolor que se torna intolerable, un sufrimiento que se vivencia como lo absoluto, no puede dejar de generar una necesidad imperiosa de descanso o alivio. Como antítesis del dolor ilimitado sobreviene la avidez vital de la nada. En esta situación límite es posible distinguir una avidez vital de la nada como manifestación pura e inmediata del padecimiento vivenciado, a diferencia de su aspiración que puede estar mediada por reflexiones abstractas. Podríamos decir que el suicidio es la mayor parte de las veces una conjunción de ambos fenómenos, es decir, tanto una desesperación por dejarse caer en una nada subjetiva, como un anhelo por alcanzarla. Lo que busco enfatizar es reconocer el estatus del sufrimiento con que se identifica aquella avidez vital de la nada que puede anteceder un suicidio, ponderando con ello aquella necesidad que puede esconderse tras la "elección" de abandonar la vida. Solo el alma sabe cuan tolerable es este o aquel dolor, y no es uno quien "decide" cuando la necesidad de la nada se ha tornado más vital que la vida misma. 
Muchas parecen ser las causas que podemos hipotéticamente suponerle al suicidio; lo cierto es que todas las razones suficientes no resultan ser a menudo fuente veraz de comprensión para quien haya sentido alguna vez compasión por alguien que lo haya cometido. Creo que muchos hombres que se figuraron, antes de suicidarse, que el cometer dicho acto podría implicar comenzar la existencia de una nueva vida, con más dificultades aún, indiferentes hubieron de pensar en ella, porque fue la propia la que se les tornó insoportable. A raíz de esto, el suicidio es realizado sin distinción de credo por personas que han sido minadas por alguna tristeza espiritual, independientemente de que ésta tenga una explicación psicopatológica o no. Este hecho me hace pensar que el acto, en estos casos, puede ser antecedido por una reflexión serena y sensata que en silencio, una y otra vez, se torna en un hábito mental que engendra esta avidez vital de la nada. Es verdad que los hábitos mentales son más fuertes que los físicos, pero necesidad no es siempre indicio de una desesperación obvia. Sin embargo, siempre nos quedamos con esto último. No hay maldad en ello, es una sensibilidad más visible, más evidente, pero no por eso menos superficial. ¿Quién no podría anhelar con nostalgia la muerte de alguien al verlo sufrir y padecer un dolor intolerable, si sabemos que dicho lamento es irreversible? Eurípides dijo una vez: $\lambda u ́ \sigma \varepsilon \imath \mu^{\prime}$ o $\delta \alpha \hat{\imath} \mu \omega \nu$ $\alpha$ ủ ó $\varsigma$, ó $\tau \alpha \nu$ \&̇ $\gamma \grave{\omega} \theta \dot{\varepsilon} \lambda \omega$ (Dios me libertará cuando yo lo desee). (Bacchae, 498). Solo veo en ello que la muerte parece ser aquí la solución al tormento de la vida.

Cuando se trata, sin embargo, de un sufrimiento de orden espiritual, el dolor muchas veces no alcanza la superficie del lamento; quienes rodeamos a este ser corremos el riesgo de permanecer como hipnotizados por aquel silencio que favorece que dichos "Hombres ante el abismo" acaben con el show de la vida y se bajen así repentina y sorpresivamente del escenario de todos los tiempos. Así como una vez hubo un Mario que fue bajado del escenario por un Mago ${ }^{1}$. Nadie se suicida solo./ Nunca nadie estuvo solo al nacer. / Tampoco nadie está solo al morir" (Artaud 1971, p. 118)². Lo cierto es que ante un suicidio, lo absurdo cobra sentido, los detalles ínfimos se pueden transformar en variantes decisivas. Se precisa un público de seres indiferentes, cuya pasividad pudo haber actuado de estímulo para acabar con el acto final y descender del escenario, donde se vive el show de la vida. Habría que saber si el mismo día que cometió un suicidio, esperaba esa persona una llamada o una carta que no recibió o simplemente un pariente o un amigo le habló con un tono indiferente.

1 Mann, Thomas, 1995, Mario und der Zauberer. Veo en la figura del Mago la voluntad de vivir y en los seudoespectadores, la hipnosis colectiva a la que puede llevar su afirmación, hasta que impávidos nos enteramos de que un hombre se ha suicidado, y nos hacemos conscientes de que fuimos uno más de los espectadores indiferentes que formábamos parte activa del espectácu10 .

2 Artaud 1971, p. 40. Artaud obró según esta premisa. "Si me mato no será para destruirme sino para reconstruirme". Para Artaud, cuando la dualidad cuerpo-espíritu se vuelve intolerable, el suicidio se presenta como el medio para abandonar el cuerpo, y avanzar heroicamente en un acto de desprendimiento hacia el riesgo mortal de quitarse la vida. Sin embargo, lo cierto es que Artaud no se suicidó. 
Schopenhauer condena el suicidio a partir de su metafísica, sin considerar que quien padece un dolor tan intenso puede olvidar todo credo o proyección de vida individual y eterna. Perpetuar la vida sería prolongar una tortura. Es precisamente mediante la $f e$ en la voluntad de vivir desde donde se reprueba el suicidio como un acto inútil y egoísta, incluso en enfermos psiquiátricos, pese a saber el filósofo qué clase de dolores comporta la locura: "La locura es el Lethe de un dolor enorme" (Schopenhauer 1990, p. 396) ${ }^{3}$, pero de un dolor que no es de orden físico. Cuando Schopenhauer anula en estos casos los efectos prácticos e inmediatos del suicidio, se aleja mediante su concatenación argumentativa no de la temática concerniente al dolor, sino que lo teoriza hasta transformarlo en una mera abstracción, y es precisamente a partir de ella desde donde legitima su condena. El suicidio no me parece de ningún modo "un acto completamente infructuoso e insensato" en el círculo de enfermedades esquizofrénicas, maníaco-depresivas u otras tantas de la misma índole (Schopenhauer 1986, Tomo I, $\S 69$, p. 542). Casos donde la persona destruye un yo, el cual no solo se le escapa, sin poder dominarlo, sino que la mayor parte de las veces se transforma éste en el peor de sus enemigos ${ }^{4}$ (Laing 1988, pp. 155-173).

En este hecho se reflejaría, según mi opinión, la imagen de la contradicción más patente que sufre la voluntad de vivir consigo misma, sería "la obra maestra de Maja", puesto que fuera de esta lucha a todo trance que se da en la diversidad de las objetivaciones, el individuo se declara, por así decirlo, la guerra contra sí mismo.

Señalo como contraargumento el caso de la locura, considerando la ausencia de condiciones que permitan acceder a un conocimiento mejor o a una conciencia continua que posibilite negar la voluntad de vivir. No debemos ignorar este hecho al ponderar, desde la crítica schopenhaueriana, el suicidio como el equívoco que se produce en el modo de enfrentar el dolor, al ser anulado con éste el único camino válido donde puede proyectarse un ideal de redención: "El sufrimiento le ronda y le abre como tal la posibilidad de negar la voluntad, pero él lo ahuyenta de sí, al destruir el fenómeno de la voluntad, el cuerpo, por lo que la voluntad permanece inquebrantable" (Schopenhauer 1986, Tomo I, § 69, pp. 542-543). En lo anterior se realza el hecho de que la voluntad no puede ser destruida más que por el conocimiento o la conciencia, y ningún acto de violencia puede aspirar jamás a dicho fin. Solo negándose la voluntad de vivir se puede acabar definitivamente con el dolor que significa el fenómeno de la vida, sin embargo, eliminando el fenómeno no se puede acabar con la esencia de ésta. Producto de ello, Schopenhauer se detiene principalmente en las consecuencias de orden ontológico, deslegitimando la eficacia inmediata del suicidio.

3 Lethe significa olvido. Pese a que Lethe hoy en día se utiliza en alemán en femenino (die Lethe), Schopenhauer se refiere a él en masculino (der Lethe), para aludir a la representación mitológica del río del olvido, del cual bebieron los muertos descendiendo al submundo del olvido (Zentner 1995, p. 222). El daño de un "dolor desmesurado" explicaría el "estropicio de la memoria" (Schopenhauer 1985, p. 88).

$4 \quad$ Prieto presenta en El socio, sensu allegorico, esta problemática. 
He aquí, paradójicamente, un "discípulo" de Schopenhauer que si bien pudo ponderar el sentido y el significado de la negación de la voluntad de vivir, fue llevado por dicha conciencia a una peligrosa antinomia, que no podemos dejar pasar por alto. El "discípulo" dice: "En febrero de 1860 llegó el día más grande, más significativo de mi vida. Entré a una librería y le eché un vistazo a los libros frescos llegados desde Leipzig. Ahí encontré El mundo como voluntad y representación de Schopenhauer. ¿Schopenhauer? ¿Quién era Schopenhauer? El nombre nunca lo había oído hasta entonces. Hojeo la obra, leo sobre la negación de la voluntad de vivir y me encuentro con numerosas citas conocidas en un texto que me hace preso de sueños" (Mainländer 2004, pp. 8-9) $)^{5}$.

En 1860, Mainländer contaba con diecinueve años. En lo que respecta a la vida de Philipp Batz (su verdadero nombre) sabemos que era el menor de seis hermanos, tres de los cuales cometieron después suicidio. Recibió su formación escolar en la Realschule de Offenbach, su ciudad natal, situada a orillas del río Main. De ahí proviene su seudónimo Mainländer (región del Main). A partir de 1856 frecuenta la escuela de comercio en Dresden. Dos años más tarde viaja por Francia hacia Italia hasta Nápoles, para ocupar un puesto en una casa de comercio. En este significativo "tiempo napolitano", de aproximadamente cinco años, es cuando descubre a Schopenhauer. A su regreso a Offenbach se hace cargo del negocio de su padre. En 1868 se traslada a Berlín donde recibe el nombramiento de "Martin Magnus" en una casa de banca. Pasados algunos años vuelve nuevamente a su ciudad natal para redactar parte de su obra principal, pero luego decide entrar voluntariamente como coracero en Halberstadt. Finalmente, en noviembre de 1875 se establece de un modo definitivo en Offenbach, para concluir el segundo tomo de su obra principal: La filosofía de la redención (Die Philosophie der Erlösung).

La filosofía de la redención no es sólo continuación de las doctrinas de Kant y Schopenhauer, sino también confirmación del budismo y del cristianismo puro. Aquellos sistemas filosóficos son rectificados y completados por ella, reconciliando además estas religiones con la ciencia. La filosofía de la redención fundamenta el ateísmo no en una creencia cualquiera como estas religiones, sino como filosofía en el saber y, por esta razón, queda el ateísmo, gracias a ella, por primera vez fundamentado de un modo científico (Mainländer 1996, Tomo I, p. VIII).

Según Mainländer, la moral cristiana no es más que un mandamiento de suicidio lento (Mainländer 1996, Tomo II, p. 218), el cual se puede lograr tomando conciencia de la caída y la decadencia profetizada como destino del mundo. Esto queda de manifiesto no solo en la vida de Cristo, sino también en la de Buda. Ambos, según el filósofo, habrían expresado el suicidio sensu allegorico a través de sus vidas.

5 Mainländer, 2004, Von Verwesen der Welt und anderen Restposten, editado por Ulrich Hostmann. Hostmann cita el ensayo de Fritz Sommerlad, "Aus dem Leben Philipp Mainländers. Mitteilungen aus der handschriftlichen Selbstbiographie des Philosophen" (1898) p. 98, en Müller-Seyfarth, 1993 
Mainländer tiene una visión propia acerca del origen del universo. Dios, saturado de su propio "super-ser", decide de un modo suicida y arbitrario la catástrofe absoluta. Conforme a ella, el universo surgió no por un deseo de creación divina, sino que fue el resultado de un agotamiento de voluntad divina. En un comienzo existe una vuelta repentina e inconcebible de perfección, sin tiempo ni espacio, que tiende hacia la nada. Increíblemente ésta es en su descarga energética lo que hoy la ciencia llamaría Big Bang. El curso irreversible de esta gran explosión se extiende, a través de su fuerza omnipotente de creación, hasta el exterminio de toda su precedencia, la cual únicamente se encuentra aún presente existiendo, pero deviniendo hacia su extenuación (Mainländer 2004, p. 15).

El hecho es que para Mainländer la conciencia advierte, a través de los tráfagos de la vida, que la no existencia es mejor que la existencia. Este conocimiento le abre al hombre la posibilidad de negar perpetuarse y tender a autoaniquilarse, para consumar finalmente el gran ciclo de la redención (Erlösung) del ser: todos somos fragmentos de un Dios, que al igual que en el "Big Bang" del principio de todos los tiempos, se destruyó, ávido de no ser: "Esta unidad simple que ha sido, ya no existe más. Ella se ha fragmentado, transformando su esencia absoluta en el mundo de la multiplicidad. Dios ha muerto y su muerte fue la vida del mundo. (...) Ya no estamos más en Dios porque la unidad simple se ha destruido y muerto" (Mainländer 1996, Tomo I, p. 108).

Mainländer, sin embargo, es consciente de sus límites: existió efectivamente una unidad simple (einfache Einheit), sin embargo no es posible descifrar en modo alguno lo que ella fue. Solo afirma que su ser fue saturado por su propio "super-ser" (Mainländer 1996, Tomo I, p. 320) y que no se asemeja a ningún ser que podamos concebir, porque todo ser que se conoce es, por el contrario, un ser cuya manifestación es movimiento o devenir.

Mainländer resume sus teorías centrales -la desintegración de la unidad en la multiplicidad, la transición del campo trascendente hacia el inmanente, la muerte de Dios y el origen del mundo- en los siguientes puntos (Mainländer 1996, Tomo I, pp. 326-327):

1. Dios quiso el no-ser.

2. Su esencia fue el obstáculo para la entrada inmediata en el no-ser.

3. La esencia tuvo que desintegrarse en un mundo de la multiplicidad, cuyos individuos tienen todos el afán de no-ser.

4. En este afán se obstaculizan mutuamente, luchan los unos con los otros y debilitan de esta forma su fuerza.

5. La completa esencia de Dios vino hacia el mundo a través de una forma transforma$\mathrm{da}$, en una determinada suma de fuerza.

6. El mundo completo, el universo, tiene una meta, el no-ser, y logra ésta mediante el continuo debilitamiento de su suma de fuerzas.

7. Cada individuo llegará a través del agotamiento de su fuerza, en su proceso evolutivo, hasta el punto que su ansia de alcanzar el exterminio pueda llegar a ser cumplida. 
De lo anterior se desprende una cosmovisión que concibe la historia universal como la oscura agonía de los fragmentos que correspondieron a un Dios y que apela, debido a ello, a la destrucción del mundo y del yo para acelerar el proceso de destrucción. "La ley del debilitamiento de la fuerza es la ley universal. Para la humanidad esta se llama ley del dolor" (Mainländer 1996, Tomo II, p. 510). En consonancia con ello, solo una teleología del exterminio es capaz de aliviar aquel dolor cuyo proceso es un padecer irreversible, por lo que solo se debe colaborar con la desintegración total del mismo: ¿y cómo lograr esto? A través de la autodestrucción o autodesintegración. Para Mainländer el dolor no es un $\delta \varepsilon v \dot{\tau} \tau \varrho o \zeta \pi \lambda$ o $\varsigma \zeta$, sino solo parte de un engranaje que se debe terminar de desintegrar. Por eso Mainländer defiende su propia metafísica: "El verdadero significado metafísico del mundo, el credo de todos los buenos y justos, es el desarrollo del mundo con la humanidad hasta el extremo. El mundo es el punto de tránsito, pero no para un estado nuevo, sino para el exterminio, el cual desde luego se encuentra fuera del mundo: ello es metafísico" (Mainländer 1996, Tomo II, p. 509).

El pesimismo autodestructivo mainländeriano transmuta el concepto de negación por el de destrucción. Voluntad de muerte (Wille zum Tod) es la conciencia de la vida como medio para alcanzar la liberación a través de la muerte. Bajo esta cosmovisión, toda cosa en el mundo es inconscientemente voluntad de muerte. El mundo se mueve "como si" tuviera una causa final, pero lo que en verdad se quiere no es la vida, puesto que ésta es solo apariencia de la voluntad de muerte. Sin embargo la redención (Erlösung) puede comenzar en vida al tomar conciencia de que lo esencial ya no es aquella voluntad que tiene como fin la vida, sino aquella que sirve como medio para la muerte. Mainländer nos habla de sí para persuadirnos de aquello: "Quisiera en adelante destruir todos los motivos fútiles que puedan amedrentar a los hombres para buscar la noche sosegada de la muerte, y cuando pueda tranquilamente quitarme de encima la existencia, cuando mi nostalgia de la muerte se acreciente sólo un poco más, entonces mi confesión podrá tener la fuerza de apoyar a cualquiera de mis semejantes en su lucha contra la vida" (Mainländer 1996, Tomo II, p. 218).

Camus en la misma línea de la confesión, casi un siglo más tarde sostiene: "Matarse, en cierto sentido, y como en el melodrama, es confesar. Es confesar que se ha sido sobrepasado por la vida o que no se la comprende" (Camus 1996, p. 16). Sin embargo, ambas confesiones difieren entre sí. El hecho es que Mainländer sí elaboró un tratado de más de mil páginas, donde incluye una minuciosa Teleología del exterminio (Teleologie der Vernichtung). En ella manifiesta su absoluta convicción de haber hallado la redención al problema de la existencia humana. "Finalmente el filósofo inmanente ve en el universo completo sólo la profunda nostalgia de un exterminio absoluto, y esto es oído por él, el llamado claro que atraviesa todas las esferas celestiales: ¡redención! ¡redención! ¡muerte a nuestra vida! Y la respuesta consoladora dice: todos ustedes encontrarán el exterminio y serán redimidos" (Mainländer 1996, Tomo I, p. 335).

El amor a la muerte de Mainländer apela a la valentía espiritual en su lucha contra la vida: 
Quien no le teme a la muerte, se precipita en una casa envuelta en llamas; quien no le teme a la muerte, sale sin vacilar en medio de un diluvio; quien no le teme a la muerte, irrumpe en una tupida lluvia de balas; quien no le teme a la muerte, emprende desarmado la lucha contra miles de titanes alzados -con una palabra-, quien no le teme a la muerte, es el único que puede hacer algo por los otros, sangrar por los otros, y recibe al mismo tiempo la felicidad única, el único bien deseable en este mundo: la verdadera paz del corazón (Mainländer 1996, Tomo II, p. 251-252).

Cuando Camus afirmó: "No hay más que un problema filosófico verdaderamente serio: el suicidio. Juzgar si la vida vale o no vale la pena vivirla es responder a la pregunta fundamental de la filosofía" (Camus 1996, p. 9), el existencialista planteó un problema que en Schopenhauer no nos conduciría jamás a la autodestrucción, sino a la autonegación. Por muy pesimista que parezca la cosmovisión schopenhaueriana, ella jamás busca el cese inmediato, violento y autodestructivo de la vida, sino, por el contrario, un camino lento de luchas internas, donde se busca negar el querer que produce el fenómeno sufriente de la vida. En esta concepción, el suicidio es antecedido por motivos que nacen de un yo volente, marcado visiblemente por las barreras individuales propias del principium individuationis, pero que más allá del fenómeno resultan ser solo una causa infundada. Precisamente porque la voluntad de vivir no vale la pena ser afirmada y nos sobrepasa en ella lo inconcebible y lo doloroso, es que se debe negar su esencia y no destruir el fenómeno particular de ella, que se vive y se vivirá siempre en uno. Paradójicamente, el apego a la vida suele ser más fuerte que todas las miserias del mundo, y aunque se juzgue que la vida no vale la pena ser vivida, son pocos finalmente los que obran según esta premisa. Esto se debe a que el querer la vida no implica más que el que se la quiera. En este hecho radica el que expongamos hoy su esencialidad. En vez de preguntarnos si la vida vale o no vale la pena ser vivida, debemos sobrecogernos simplemente con el hecho de que la vida nunca ha resultado ser vivible para todo ser humano.

Camus afirma que ve morir a muchas personas porque estimaron que la vida no vale la pena ser vivida, pese a que tuvieron la convicción en algún momento que sí era valioso hacerlo. Sin embargo, afirma: "Nunca vi morir a nadie por el argumento ontológico. Galileo, que defendía una verdad científica importante, abjuró de ella con la mayor facilidad del mundo cuando puso su vida en peligro" (Camus 1996, p.14). Klaus Thomas, en su libro Hombres ante el abismo, parece ser más cauteloso al recordar a Hegesias, a quien se le dio el significativo apodo de Peisithánatos, en la medida en que, como lo dice su nombre, era un hombre que precisamente persuadía a matarse, y esto mismo hizo él, porque creía que la felicidad tan frecuentemente ensalzada por los hombres era simplemente inasequible y nunca jamás alcanzada. Sin embargo, Klaus Thomas también se manifiesta algo vacilante: "Hay pocos que estarían dispuestos a morir por una demostración ontológica" (Thomas 1970, p. 28).

¿Puede en verdad morir alguien por un argumento ontológico? Volvamos al año 1876. Precisamente el primero de abril, el día de la víspera de la impresión de la Philosophie der Erlösung, Philipp Mainländer acabó con su vida. Con los escritos de su obra levantó un cúmulo de papeles que utilizó como pedestal, como base de su 
redención filosófica. Me lo represento colgando la cuerda en la viga y rodeando con el lazo mortífero su cuello. Luego comienza con el movimiento de las piernas.

Los físicos podrán ponderar hoy y mañana la agudeza de su sensibilidad para expresar vivencial y consecuentemente lo que hoy la ciencia llamaría Big Bang, o también el aumento de la entropía, fuera de todos los aportes que pudo expresar así, concernientes a la teoría del caos y los postulados que dicen relación con las leyes de la termodinámica. Sin embargo, me doy cuenta de que el Big Bang o la teoría de la gran explosión matematiza y salda la fantasía mitopoética destructiva del "comienzo-final" catastrófico, el cual fue vivenciado por Mainländer como suicidio. Este hecho nos permite reconocer a la par su sensibilidad mitopoética como expresión de su dolor vivenciado y teorizado. Ironizar que su suicidio fue un acto perpetrado para enaltecer su obra es un juicio que no concierne en este caso a una reflexión que busca ser consciente de la esencialidad propia de su vivencia. Realzo en ella su sensibilidad mitopoética: "más allá del mundo no hay ni un lugar de paz ni un lugar de tormento, sino sólo la nada. (...) Esto puede generar un nuevo contramotivo y un nuevo motivo: esta verdad puede hacerlo retroceder a uno hasta la afirmación de la voluntad, y a otro puede llevarlo poderosamente hasta la muerte" (Mainländer 1996, Tomo I, pp. 350$351)$.

Este ensayo sobre el suicidio, a la luz de la voluntad de vivir y la voluntad de morir, fue concebido como intento de profundizar y comprender, a partir de dos teorías antagónicas, una argumentación ontológica que lo condena y otra que lo legitima, hasta la radical consecuencia de consumarse en su praxis. El supremo cumplimiento que ha de atreverse a acometer el suicida es la abdicación en pro de la nada, cuyo llegar a ser lo anula él mismo, anulándose a sí mismo como resultado de una avidez vital de la nada que se trasciende a sí misma.

\section{Referencias bibliográficas}

Artaud, Antonin (1971), Van Gogh el suicidado por la sociedad. Buenos Aires: Editorial Argonauta.

Camus, Albert (1996), El mito de Sísifo. Madrid: Alianza.

Claudius, Matthias (1974), Auf einen Selbstmörder. Stuttgart: Deutscher Bücherbund. Eurípides (1982), Bacchae. BSB. Leipzig: Teubner.

Laing, Ronald. D. (1988), El yo dividido: Un estudio sobre la saludy la enfermedad. Ciudad de México: Fondo de Cultura Económica.

Mainländer, Philipp (1996), Die Philosophie der Erlösung. Tomos I y II. Hildesheim: Georg Olms.

(2004), Von Verwesen der Welt und anderen Restposten, Leipzig: Edition Sonderwege bei Manuscriptum.

Mann, Thomas (1995), Mario und der Zauberer: Ein tragisches Reiseerlebnis. Frankfurt a. M.: Fischer Taschenbuch Verlag. 
Müller-Seyfarth, Winfried (1993), "Die modernen Pessimisten als décadents": von Nietzsche zu Horstmann. Texte zur Rezeptionsgeschichte von Philipp Mainländers Philosophie der Erlösung. Würzburg: Königshausen und Neumann.

Prieto, Jenaro (1980), El socio. Santiago de Chile: Editorial Andrés Bello.

Schopenhauer, Arthur (1985), Der handschriftliche Nachlaß, "Frühe Manuskripte" (1804-1818). Tomo I. München: Deutscher Taschenbuch Verlag.

(1986), Die Welt als Wille und Vorstellung I. Sämtliche Werke. Tomo I. Stuttgart / Frankfurt: Suhrkamp Taschenbuch Verlag.

(1990), Vorlesungen über die gesammte Philosophie, d.i. die Lehre vom Wesen der Welt und von dem menschlichen Geiste. In vier Theilen. Erster Theil: Theorie des gesammten Vorstellens, Denkens und Erkennens. München: Pieper.

Thomas, Klaus (1970), Menschen vor dem Abgrund, Ein Arzt und Psychotherapeut berichtet aus der Praxis der Selbstmordverhütung. Hamburg: Christian Wegner Verlag.

Zentner, Marcel (1995), Die Flucht ins Vergessen: Die Anfänge der Psychoanalyse Freuds bei Schopenhauer. Darmstadt: Wissenschaftliche Buchgesellschaft. 